\title{
In the Classroom
}

\section{Pronunciation Pegs}

\section{Carolyn Samuel}

An ESL instructor describes her experience of using pronunciation pegs, a method to foster the self-monitoring and self-correction of pronunciation mistakes with a view to helping university-level students deal with the ongoing challenge of producing target-like pronunciation. The appeal of pegs to students led the instructor to reflect on what makes adopting target pronunciation problematic, how pegs can be adapted to various learning styles, and how cultural differences can have an effect on the appreciation of pegs. Finally, the instructor sought a theoretical explanation for how pegs worked and found this in anchoring and covert rehearsal.

Une enseignante en ALS décrit son expérience avec l'utilisation d'une méthode basée sur l'autosurveillance et l'autocorrection des erreurs de prononciation et conçu pour appuyer les étudiants à l'université dans leurs efforts continus de produire des sons cibles. L'attrait du système, pour les étudiants, a provoqué chez la professeure une réflexion sur la difficulté de prononcer les sons cibles, sur les façons d'adapter le système aux divers styles d'apprentissage et sur l'effet des différences culturelles relatives à l'appréciation du système. Finalement, la professeure a cherché une explication théorique pour le fonctionnement du système; elle l'a trouvée dans l'ancrage et la répétition interne.

\section{Introduction}

Consistent production of target pronunciation is a challenge for many second-language-learners. Without immediate feedback from a teacher, and even with active monitoring (Krashen, 1982), learners are often uncertain if they have succeeded in producing targeted sounds or prosodic patterns. To help learners manage such uncertainty and develop the skill and confidence necessary to become increasingly independent with their language-learning, they can be taught strategies "to monitor their production through the teaching of formal rules, feedback and reflective activities" (Jones, 1997, p. 107). Such pronunciation strategies have been documented in materials published by Morley (1979), Acton (1984), Bradford (1988), Crawford (1987), Firth (1987), Pennington (1996), and Wong (1987, all cited in Jones, 1997).

This article describes pronunciation pegs, an in-class teaching/learning strategy to help learners develop their ability to self-monitor and self-correct with a view to adopting target pronunciation; next, it describes how pronun- 
ciation pegs are relevant to learning styles; and finally, it offers two theoretical explanations for how pronunciation pegs function to foster self-monitoring and self-correction.

\section{The Problem of Adopting Target Pronunciation}

Among adults, there are at least four reasons why learners may experience difficulty adopting target pronunciation. First, they may lack the knowledge of certain auditory features of pronunciation. In other words, a learner may not have heard or noticed a particular sound or other linguistic feature. This awareness is important because

the ability to process, segment, and decode speech depends ... also on being able to exploit knowledge of the sound system.... In addition to carrying out [several] strategies when listening to spoken English, nonnative speakers have to overcome other hurdles, among them lack of knowledge of the sound system. (Celce-Murcia, Brinton, \& Goodwin, 1996, p. 222)

An example of an auditory feature that learners are often unaware of is linking: words are linked in English to produce connected speech. In connected speech, words are joined such that a phrase may sound like one word. There are diverse linking patterns such as consonant + vowel, where a word ending in a consonant sound is linked to a word beginning with a vowel sound, for example, an animal is pronounced as $a_{\sqcup}$ nanimal. Another example is vowel + vowel, where a word ending in a vowel sound is linked by the addition of a semi-vowel to a word beginning with another vowel sound, as in see ${ }^{y}$ it. Vowel + vowel links also occur in words where adjacent vowels are produced as separate syllables, as in $\mathrm{CO}^{\mathrm{w}}$ operation and $\mathrm{cre}^{\mathrm{y}}$ ate. A learner who is unaware of linking may produce choppy, unconnected speech in English. This is the case, for example, with most of my Chinese-speaking (Mandarin and Cantonese) students. Generally, they say they have difficulty aurally discerning linked sounds, particularly from word to word, because they are unfamiliar with this feature or trait of English. Swan and Smith (2001) explain why linking poses a challenge for Chinese L1 speakers learning English: "The monosyllabicity of basic Chinese units leads to learners' separating English words rather than joining them smoothly into a 'stream of speech'"' (p. 313).

Second, even when a learner's attention is directed to a particular sound or other feature of pronunciation, not all learners can readily hear it. As Celce-Murcia et al. (1996) explain, the obstacles learners face when trying to decode language "can distort their perception when they listen to English" and "may contribute not only to word-level perception errors ... but also to phrase level mishearings" (p. 223). This is especially true in the case of adults whose first-language phonological systems are well ingrained. What they 
hear is often filtered through their L1. In other words, accurate hearing may be affected by a learner's L1. I became particularly aware of this when learning Korean. To my ear, there are two letters of the Korean alphabet that are pronounced with an imperceptible difference: the letter kiok [ $\neg](/ \mathrm{g} /$ or $/ \mathrm{k} /$ ) and sang [double] kiok [ 77 ] (kk), which is approximately a glottalized $/ \mathrm{k} /$ sound. English does not have this sound combination. Although I knew there were two letters, and despite intensive aural drilling, I could not differentiate the sounds in a dictation. And without being able to hear the difference, I was unable to produce the two sounds orally.

The third reason is L1 interference at the level of production. First language interference, namely, the "tendency to transfer the rules and features of [one's] first-language sound system to English" (Celce-Murcia et al., 1996, p. 223), may result when there is a linguistic feature that does not exist in the L1 but does exist in the L2. It is possible a learner will hear a different pronunciation but not be able to pronounce it. An example of this is the production of the [th] sounds $/ \theta /$ and $/ \partial /$ in English. Depending on the learner's L1, the voiceless sound $/ \theta /$ is frequently substituted by voiceless sounds /t/, /s/, or /f/ and the voiced sound /ð/ by /d/, /z/, or /v/ (Avery \& Ehrlich, 1992). The place of articulation for these two sounds, namely, the tongue between the upper and lower teeth, is uncomfortable for learners to produce if they do not have sounds in their L1 with an identical place of articulation. Thus second-language learners may understand the two [th] sounds, but because these sounds do not exist in the L1, learners may not readily be able to replicate them.

Finally, the low sound/spelling correspondence in English can affect pronunciation (Schmitt \& Marsden, 2006, see the section on "Mismatches between Pronunciation and Spelling in English"). As illustrated in Figure 1, one grapheme (written letter) may represent several phonemes (sounds).

Vowel graphemes and the phonemes they represent
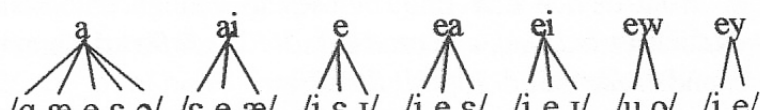

$/ \mathrm{a} æ \mathrm{e} \varepsilon \mathrm{s} / / \varepsilon$ e æ/
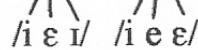

/i e i/ /u ol /i el
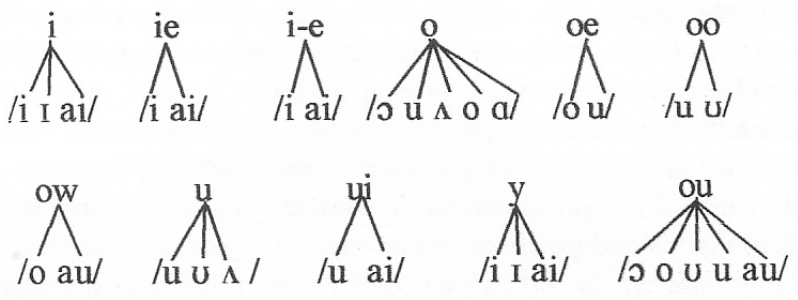

Figure 1. (Teschner \& Whitley, 2004, p. 126). 
Consider, for example, the letter $a$. It is pronounced differently in each of the following words: cat /æ/, game /el/, law /ə/, father /a/, and amount /ə/.

The numerous grapheme/phoneme possibilities in English present an ongoing pronunciation challenge for many English second language learners who may be able to recognize written forms but not know how to pronounce them.

Adult learners generally understand these challenges when they are explained. Yet even with this understanding, they are not necessarily skilled at aurally discerning and/or producing target pronunciation. I use pronunciation pegs as a strategy for coaching learners to develop their ability to self-monitor with a view to being able to produce target pronunciation during in-class practice.

\section{Pronunciation Pegs}

Pronunciation pegs is the name I have given to a technique I use to help my university-level students deal with problems associated with adopting target pronunciation. These students fall into two categories: (a) ESL graduate students from a variety of academic disciplines and L1s who take a course in pronunciation and communication; and (b) BEd TESL students who take a course in how to teach oral skills and who in Quebec (where I teach) may be anglophone, francophone, or allophone. Thus although all the TESL students are learning how to teach pronunciation, many are themselves learning how to improve their own pronunciation. Although the learning perspective may not be uniform for both student populations, I use the same technique (a type of aide mémoire) with both to remind them efficiently what the target pronunciation is.

Using pegs can be thought of as a mnemonic strategy (Firth, 1987): mnemonic strategies "relate one thing to another in a simplistic, stimulus-response manner" (Oxford, 2001, p. 167). The relationships must nonetheless have some connection to the learner's existing knowledge. Without any connection or meaningful association, there is no memory aid. Examples of popular mnemonics are HOMES, to remember the Great Lakes (Huron, Ontario, Michigan, Erie, Superior) and Father Charles Goes Down And Ends Battle, to remember the order of sharps (F, C, G, D, A, E, B) in key signatures in music. Such mnemonics are popular because they are an efficient way to remember something potentially complex.

\section{Example Pegs}

In an effort to minimize teacher intervention and increase learner selfreliance where pronunciation correction is needed, I have increasingly been using pegs to jog learners' memories of the target pronunciation. A popular peg among my students comes from Gilbert's (1994) rubber band technique for practicing primary stress. After students have learned to stretch the 
rubber band on the syllable with primary stress, I or their peers mimic the action-without the rubber band-when a student makes a primary stress mistake in order to indicate to the speaker that primary stress belongs on another syllable. Other popular kinesic pegs such as hand motions to indicate intonation patterns can be found in Lewis and Hill (2002), and in Firth (1987). Firth suggests that learners "can be encouraged to 'walk' through sounds in the way one walks through a new dance step. For example, with /f/, lower the upper teeth against the lower lip, tense the lip slightly and blow out" (p. 149). Knowing this sequence allows the learner "to retrace the steps in producing the sound in order to check whether all steps were passed through correctly" (p. 149). In addition to this walk through in a classroom situation where a learner has mispronounced the /f/ sound, a teacher can hold up three fingers to remind the learner that there are three steps to retrace in order to produce the sound correctly.

Below are examples of pegs I have used with my students to prompt correction of both suprasegmental (stress, rhythm, and intonation) and segmental (phoneme) features of pronunciation.

- Making a cutting (scissor-like) gesture to prompt word stress correction:

The word unique has primary stress on the second syllable. Learners frequently mispronounce the word by putting primary stress on the first syllable, thus pronouncing a word that sounds similar to eunuch. Most of my students are unfamiliar with this word. When I explain the meaning, I make a gesture to indicate cutting by moving two fingers. This cutting or scissor gesture becomes a peg for word stress in general. Thus if my students make mistakes with word stress in any word, I make the scissor gesture to let the student know to shift primary stress to another syllable.

- Touching my necklace to prompt linking: I explain to students that a necklace has links. If students neglect to link words in a sentence or to link sounds in words, I touch my necklace.

- Pointing to my eye for vowel correction: If my students mispronounce words such as height and aye (where they say /heit/ for / hait/ and /eI/ for /aI/) because they are confused by the spelling, I explain that the sound rhymes with the word eye. Thus if a learner mispronounces the vowel sound /aI/, I point to my eye to indicate that the sound produced is not accurate and should be modified.

Not all pegs involve gestures. An auditory reference to a peg is also useful.

- Saying Pablo for vowel correction: Spanish speakers tend to approximate certain vowel sounds because more than one English vowel may "share the 'phonetic space' occupied by one Spanish ... vowel" (Swan \& Smith, 2001, p. 91). An example is the vowel sound $/ \wedge /$, as in company, which corresponds roughly to the Spanish /a/. I tell students that a speaker of General North American English pronounces 
the vowel sound $/ \wedge /$ similarly to the [a] in the Spanish name Pablo.

Once learners understand this, I simply say Pablo when they

mispronounce a vowel that should sound like the [a] in Pablo.

Generally, I introduce a peg at the time of instruction (focus on form). For example, most of my ESL students are unaware of the concept of primary stress, and most place primary stress on the wrong syllable in at least some words. At the time of instruction, I explain the concept of primary stress, I demonstrate target pronunciation with several words, and then I may introduce a peg to illustrate and reinforce the target. Thus when I introduce a peg, I have to be sure that the connection with the target pronunciation is explicit. Otherwise, the students will later not make an association with existing knowledge and will be unable to work toward the target pronunciation. During an activity where students are practicing target pronunciation, I will intervene if necessary with that same peg to correct the form being practiced, but I will not intervene with a peg related to other forms that students have practiced. Although I monitor when I use pegs during practice activities, students are free to invoke a peg with their peers at any time. I am always delighted to see this, as it is evidence of students' language awareness.

Instruction, however, is often spontaneous because it can be prompted by students' in-class utterances. This is sometimes the case with my ESL students, but it is almost always the case with my TESL students. Any time a student utters a typical L1 interference type of mispronunciation, such as a Spanish speaker's pronunciation of the $o$ in company or a francophone speaker's lack of pronunciation of the semi-vowel in the phrase "I see it" (producing "I see hit" instead of "I see ${ }^{y} i^{\prime \prime}$ "), I may interrupt to explain the target pronunciation and introduce a peg to illustrate and reinforce it. I do not assume that there will be L1 interference; I act if the utterances occur. In fact, I view these occurrences as teachable moments. Once the peg has been introduced, I or my students may use it at any opportune moment during class time as a reminder of the target pronunciation.

Pegs can be created spontaneously or they can be planned by both teachers and learners. Most of the pegs I use originally evolved spontaneously during classroom interaction. Over time, I have developed a repertoire of pegs that I now use consciously, and when I use a peg, I explain to students what I am doing, why I am doing it, and how it is intended to benefit them. Meaningful and effective pegs can also come from learners during classroom activity. As learners practice producing a certain sound or prosodic feature in class, they may make a spontaneous gesture, perform some other body movement, or utter a phrase that becomes associated with that learning and thus becomes a peg. 


\section{Learning Styles and Cultural Differences}

Not every peg will be useful for every learner because individuals perceive and interpret images, gestures, and language in varying ways. This reality led me to consider the appropriateness of the pegs that I use with respect to diverse learning styles. Some work well with auditory learners, for example, saying Pablo, whereas others work well with visual learners such as touching the links of a necklace; yet others such as Firth's (1987) example of retracing steps may be useful for kinesthetic learners. In addition to ensuring that learners with all learning styles can access pegs, an awareness of the value of tapping into diverse learning styles allows a teacher to help learners broaden how they experience language. As Acton (1997) explains,

The implication for pronunciation work is that we do not have to be overly concerned that we "give" everybody their favorite modality, because we should be using a multi-modality approach in the first place. In other words, every sound process should be experienced as a totality: visual + auditory + kinesthetic + tactile (although not necessarily in that order, of course). In that way learners have the opportunity to strengthen their "lesser" modalities. (§ Suggestion Five)

An activity for teachers as well as for students is to review learning styles (diverse approaches or ways of learning) such as those drawn from Brown (2000, see summary below); and then either try to adapt existing pegs to each style or try to create a peg for several learning styles to deal with a common or recurring pronunciation problem.

I asked my TESL students to do this activity. One kinesthetic suggestion came from a student who introduced an s-like body wave motion as a peg for when learners forget to pronounce final [s] (third person singular and plural forms). Subsequently, this peg came to be used in our class among peers such that they offered it as a reminder to each other. Sometimes this was to remind a nonnative speaker in the class, and at other times it was to practice using pegs in a teacher role.

At their Web site Sounds of English, Gray, Taylor, and Thompson (2001) offer pronunciation practice activities that encourage learners to demonstrate their knowledge and ability according to their preferred learning style (the specific page is called Pronunciation with an Eye on Multiple Intelligences).

Table 1

Summary of Learning Styles (Brown, 200, pp. 113-122)

$\begin{array}{ll}\text { field independent } & \text { field dependent } \\ \text { tolerant of ambiguity } & \text { intolerant of ambiguity } \\ \text { reflective } & \text { impulsive } \\ \text { left-brain functioning } & \text { right-brain functioning } \\ \text { visual } & \text { auditory }\end{array}$


Multiple intelligences is a reference to Gardner's (1993) theory of the seven ways of knowing or of demonstrating intellectual ability. Gray et al. suggest pronunciation practice activities designed for learners with the following learning styles or intelligences: bodily/kinesthetic, logical/mathematical, interpersonal, intrapersonal, musical, visual/spatial, and naturalistic (see Silver, Strong, \& Perini, 1997, for a discussion of the integration of learning styles and multiple intelligences.)

When using pegs, the teacher must also keep in mind that cultural differences have a bearing on the appreciation of pegs. Not all gestures or sounds have universal meanings. For example, in North American English culture/language, the quasi-word achoo denotes a sneeze. A pronunciation teacher might, therefore, mime a sneeze in the case where a learner has difficulty pronouncing the consonant sound $/ \mathrm{t} \int /$, saying sherry, for example, instead of cherry. However, miming a sneeze as a reminder of the $/ \mathrm{t} \int /$ sound in achoo may have little meaning for a learner who is from a culture where achoo either does not exist or is not associated with a sneeze. Another example of a peg that is culture/language-dependent is placing the index finger vertically across the lips and saying $\operatorname{shh}\left(/ \int /\right)$ to indicate "quiet." This peg is potentially useful for learners who have difficulty producing $/ \int /$, saying mess, for example, instead of mesh. However, for a learner who is unfamiliar with the gesture and accompanying sound, the peg will probably be ineffective for getting a learner to produce a $/ \int /$ sound. Yet raising awareness of such sound-meaning correspondences may inspire teachers to capitalize on these pegs as an opportunity for teaching culture as well.

\section{Theory to Support the Use of Pegs}

Because pegs are intended to help learners develop the ability to self-correct, it is worthwhile making a distinction between the terms mistake and error. A mistake can be considered a slip, that is, a wrong response due to forgetfulness or inattentiveness. If one thought about the mistake, one would be able to correct it. An error is considered a wrong response due to lack of knowledge. A learner would probably not be able to correct an error because he or she lacks knowledge of the correct form. If prompted, a learner has the potential to correct a mistake; however, a learner has no potential to correct an error until he or she learns the correct form (Corder, 1967; Watkins, 2005). Because pegs depend on recall, that is, they serve as reminders for material that students have already learned, they will be effective only in the case of mistakes and not in the case of errors. Therefore, self-monitoring and selfcorrection imply that a learner has knowledge of correct forms.

It was only after using pegs in the classroom and observing their popularity among learners that I sought to understand their appeal. I found two explanations (although there are undoubtedly others) that were pertinent: (a) the concept of anchoring, and (b) the concept of covert rehearsal. The first, 
anchoring (Bandler \& Grinder, 1979), is a concept related to the field of neurolinguistic programming (NLP). Anchoring is thought to work along the lines of classical conditioning whereby an external stimulus is used to trigger a particular memory such as a thought or a feeling with a view to modifying behavior. The stimulus can be truly external such as a phrase uttered by someone else, a sight or sound, or it can be internal such as talking to oneself. Anchoring thus helps to explain how mnemonic devices work. In his electronic article "Seven Suggestions of Highly Successful Pronunciation Teaching," Acton's (1997) sixth suggestion is to "Anchor well." He explains, "'Anchoring' is, in some sense, the basic idea in hypnosis: Do something striking so that 'it' is remembered or forgotten ... From an NLP standpoint it means first, ensuring concentration ... and then bringing together the right combination of modalities to 'set' the memory" (§ Suggestion Six). Acton goes on to explain:

Anchoring ... may mean just "giving" the learner a phrase that contains the new sound or process, in some vivid and memorable context to "carry home." The NLP-oriented instructor would plan for that kind of closure, making it a top priority.... Especially with pronunciation work, if you do not have time to anchor a sound change or process well (Present and practice it so it will be remembered!) don't bother with it... Pronunciation change, especially in a classroom, must be a focused, multi-sensory and multi-modal experience which is well anchored.

(§ Suggestion Six)

I do my best to afford learners opportunities for extensive practice during class time. Not only do I encourage practice, but I also frequently repeat the target so that learners have aural input as an anchor with a view to producing the targeted pronunciation. In fact, aural input as a set memory has been found to be a popular pronunciation strategy. Through oral protocols, Osburne (2003) investigated strategies used by advanced ESOL learners for monitoring and improving pronunciation. Of the eight strategies that emerged from interviews with the participants, the most commonly used was focus on "memory or imitation" (p. 137). This strategy entailed attempting to "mimic the interviewer or other speakers heard on previous occasions" (p. 136). Being able to retrieve target pronunciation from memory would indicate that it was anchored.

Second, covert rehearsal (Dickerson, 1989, cited in Murphy, 1991) refers to a meta-cognitive learning strategy that entails "training ESL learners to selfmonitor their private speech" (Murphy, p. 67). It is the process whereby before producing an utterance, the learner rehearses the correct language form(s) in his or her mind. Murphy explains:

While best suited to the kind of student Krashen (1982) has termed the "optimal Monitor user" (p. 19), it involves critical self-evaluation and 
self-correction in either classroom or nonclassroom settings. During moments of covert rehearsal a learner applies to self-initiated utterances his/her knowledge of past learning and memories of target language sounds. (p. 67)

I have discussed this strategy with my students, and although they are unfamiliar with the term covert rehearsal, many agree that they do it (for a more detailed description of covert rehearsal and how to use the strategy, see Hahn \& Dickerson, 1999a, 1999b).

\section{Conclusion}

English-as-a-second-language learners encounter a variety of challenges when trying to improve their pronunciation. Pronunciation pegs, which can be adapted to a variety of learning styles, can be created by teachers and language learners and initiated by teachers or classroom peers. Both my ESL and TESL students have commented on the positive effect the technique has had on their self-confidence as they realized they they did not need to rely solely on a teacher for feedback. They also felt better equipped to self-monitor and self-correct spoken language in order to deal with challenges associated with producing and teaching target pronunciation.

\section{Acknowledgments}

I am grateful to Lise Winer for useful comments on a draft of this article and to my colleague Natallia Liakina for sharing her necklace/linking peg.

\section{The Author}

Carolyn Samuel teaches English for academic purposes (EAP, oral and written) at the English and French Language Centre in the Faculty of Arts at McGill University and oral skills methodology in the Faculty of Education. She is a recent recipient of the Principal's Prize for Excellence in Teaching (Faculty Lecturer category).

\section{References}

Acton, W. (1997, February). Seven suggestions of highly successful pronunciation teaching. Language Teacher Online, 21(2). Retrieved January 1, 2008 from: http://jalt-publications.org/tlt/files/97/feb/seven.html

Avery, P., \& Ehrlich, S. (Eds.) (1992). Teaching American English pronunciation. Oxford, UK: Oxford University Press.

Bandler, R., \& Grinder, J. (1979). Frogs into princes: Neurolinguistic programming. Moab, UT: Real People Press.

Brown, H.D. (2000). Principles of language learning and teaching (4th ed.). White Plains, NY: Pearson Education.

Celce-Murcia, M., Brinton, D.M., \& Goodwin, J.M. (1996). Teaching pronunciation: A reference for teachers of English to speakers of other languages. Cambridge, UK: Cambridge University Press.

Corder, S.P. (1967). The significance of learners' errors. IRAL, 5, 161-170.

Firth, S. (1987). Developing self-correcting and self-monitoring strategies. TESL Talk, 17(1), 148-152.

Gardner, H. (1993). Multiple intelligences: The theory in practice. New York: Basic Books. 
Gilbert, J. (1994). Intonation: A navigation guide for the listener (and gadgets to help teach it). In J. Morley (Ed.), Pronunciation pedagogy and theory: New views, new directions (pp. 36-48). Alexandria, VA: TESOL.

Gray, H., Taylor, K., \& Thompson, S. (2001). Pronunciation with an eye on multiple intelligences. Paper presented at WATESOL Convention, Annandale, VA. Retrieved January 6, 2008, from:http://www.soundsofenglish.org/Presentations/WATESOL2001/ multipleintelligencesactivities.htm

Hahn, L.D., \& Dickerson, W.B. (1999a). Speechcraft: Discourse pronunciation for advanced learners. Ann Arbor, MI: University of Michigan Press.

Hahn, L.D., \& Dickerson, W.B. (1999b). Speechcraft: Workbook for international TA discourse. Ann Arbor, MI: University of Michigan Press.

Jones, R.H. (1997). Beyond "listen and repeat": Pronunciation teaching materials and theories of second language acquisition. System, 25(1), 103-112.

Krashen, S. (1982). Principles and practice in second language acquisition. Oxford, UK: Pergamon.

Lewis, M., \& Hill, J. (2002). Practical techniques for language teaching. Hove, UK: Language Teaching Publications.

Murphy, J. (1991). Oral communication in TESOL: Integrating speaking, listening and pronunciation. TESOL Quarterly, 25, 51-75.

Osburne, A.G. (2003). Pronunciation strategies of advanced ESOL learners. IRAL, 41, 131-143.

Oxford, R.L. (2001). Language learning strategies. In D. Nunan \& R. Carter (Eds.), The Cambridge guide to teaching English to speakers of other languages (pp. 166-172). Cambridge, UK: Cambridge University Press.

Schmitt, N., \& Marsden, R. (2006). Why is English like that? Historical answers to hard ELT questions. Ann Arbor, MI: University of Michigan Press.

Silver, H., Strong, R., \& Perini, M. (1997). Integrating learning styles and multiple intelligences. Educational Leadership, 55(1), 22-27.

Swan, M., \& Smith, B. (Eds.) (2001). Learner English: A teacher's guide to interference and other problems (2nd ed.). Cambridge, UK: Cambridge University Press.

Teschner, R.V., \& Whitley, M.S. (2004). Pronouncing English: A stress-based approach with $C D-R O M$. Washington, DC: Georgetown University Press.

Watkins, P. (2005). Learning to teach English: A practical introduction for new teachers. Surrey, UK: Delta. 